\title{
DEVELOPMENTAL ASPECTS OF SHOULDER CONTROL
}

\author{
S. H. IRWIN-CARRUTHERS, Nat. Dip. Physio., Dip. Physio. Ed. (U.P.)*
}

\section{SUMMARY}

In recent years much more allention has been paid to the actual components of movements which are built up during the! motor development of the infant, rather than to mere' documentation of milestones. Motor control of the scapula and. gleno-humeral joint is essential to the development of all upper. linb function. Recognition of the exact movement components, involved and the order in which they develop provides a basis for more accurate assessment of disability and planning of treatment.

For many years physiotherapists have been accustomed to studying motor development as a series of milestones or, possibly, stepping stones (Sheridan, 1981). It is only recently that attention has been paid to the actual components of movement involved in these different developmental patterns, and to the natural history of these components as they are built up, modified and perfected over a period of timc. Many of the earlier patterns are prerequisites for the development of more advanced patterns. Following disability, whether orthopaedic or neurological, it may be necessary to identify the exact components of movement involved and re-educate these in developmental sequence in order to restore optimal function.

The functions of the upper limb can be grouped under two headings, namely manipulative (including sensory functions and emotional expression) and weight-bearing (including protective). Although of prime importance in young children, the weight-bearing/protective function is of Iesser importance in the adult with adequately developed equilibrium reactions. More important is that the failure to develop weight-bearing function, or to re-establish this after injury or disease, appears to interfere with the later development of manipulative ability. The key to the development of all weight-bearing and manipulative abilities lies in the components of movement established at the shoulder girdle and glenohumeral joint. These, in turn, are linked to the central control of flexion and extension against gravity. In this the righting reactions play the primary role although other influences are seen in the course of development. Initially the movements of the scapula and gleno-humeral joint are linked and the baby can not move the one independently of the other in order to break up movement synergies. As control of the various components is established the ability to dissociate movements of scapula and humcrus develops.

Central control of head and trunk is also important in determining the ability to bring the arm across the midline of the body. The child cannot do this until he has learnt to rotate the upper trunk on the pelvis; he crosses the midline with his upper trunk before he can truly bring his arm across the midline.

For the sake of simplicity, in this article the term adduction of the scapula will be used to describe the combination of retraction and medial rotation, and the term abducrion to describe the combination of protraction and lateral rotation.

\footnotetext{
* Senior Lecturer and Acting Head of Dept., University of Stellenbosch.

Received 18 February 1982.
}

\section{OPSOMMING}

Die afgelope paar jaar word, pleks van blote dokumentasie van mylpale, ook heelwat aandag geskenk aan die bepaalde bewegingskomponente wat gevorm word tydens die motoriese onlwikkeling van die kind. Moloriese beheer van die skapula en glenohumerale gewrig is noodsaaklik wir die onlwikkeling wan alle funksies van die boonste ledemate. Herkenning van die presiese bewegingskomponenle, asook die volgorde waarin hulle onwikkel, bied 'n grondslag vir meer akkurale evaluering van gebreke en beter beplanning van behandeling.

\section{DEVELOPMENT OF COMPONENTS OF MOVEMENT AT THE SHOULDER GIRDLE AND GLENO-HUMERAL JOINT}

In the newborn the scapulae are elevated in all resting positions; the baby apparently has no neck. In the prone position there is rather more abduction of the scapula as a result of the influence of the primitive tonic labyrinthine reflex. Casaer (1979) describes strong, active mass flexion movements in the awake baby in which the scapula abducts and the humerus adducts and internally rotates. In supine there is relatively more adduction of the scapula, again secondary to the influence of the tonic labyrinthine reflex, with slightly less adduction and internal rotation of the humerus. The elbows usually do not rest on the surface and if the hand contacts the mouth sucking may occur, resulting in a tendency towards more abduction of the scapula with increased adduction and internal rotation of the humerus. Some active postural control against gravity is assumed, but it is uncertain whether prolonged maintenance of these postures is due to sustained postural activity or to viscoelastic properties (Casaer, 1979). As the baby falls asleep in supine, the scapulae become more adducted and the arms fall into more abduction and external rotation.

As extension develops cephalo-caudally there is progressively less elevation of the scapulac and the neck appears longer. Since extensor control develops slightly a head of flexor control the scapulae become more adducted in both prone and supine, bringing the arms with them into abduction. The control required for weight-bearing starts to develop early. By three months of age cxtension has sprcad throughout the whole thoracic area and the baby can stabilise well enough with his scapulae in adduction in the prone position to start weight-bearing on his elbows with the humerus in abduction and internal rotation. As control of flexion increases there is more active depression and abduction of the scapulae in prone, bringing the humerus into more adduction and therefore more external rotation. By four months the baby has good control of either adduction or abduction of the scapula in prone but cannot dissociate movements of scapula and humerus. When the scapula is adducted the humerus goes into abduction and external rotation (the swimming pattern) whilst when the scapula is abducted the humerus is drawn into adduction, the degree of internal or external rotation being dependent upon the position of the hands on the floor. As he starts to push up onto extended arms he initially reverts to stabilising with adduction of the scapula and with abduction and internal rotation of the humerus. As he pushes more strongly flexor activity increases, resulting in more abduction of the scapula and more adduction and external rotation of the humerus. 
Once the development of extensor and flexor control becomes balanced, the baby starts to shift weight in preparation for reaching. At first he tries to stabilise with adduction of the scapula on the weight-bearing side and, until he lcarns to compensate with lateral flexion of the trunk on that side, he falls to the non-weight-bearing side. Propping with lateral trunk flexion, adduction of the scapula and adduction of the humerus on the weighl-bearing side is a perfectly normal pattern seen in carly attempts to reach, but the baby will not be able to move his body freely over the supporting limb until he can stabilise his scapula adequately in abduction. As this control develops he extcnds his trunk on the weight-bearing side and, as he rotates his trunk on the supporting arm. the humerus becomes progressively more abducted and externally rotated. This apparent dissociation is, at this stage, due to fixation of the distal segment rather than active isolation of components of movement.

Development of reach runs parallel but fractionally behind that of support. In supine the baby starts to reach forwards at about four months. At first flexor control is inadequate to allow abduction of the scapula and the shoulders rest on the ground. He reaches with internal rotation of the humerus. With increasing flexor control the shoulders begin to lift from the ground as the scapulae abduct against gravity. He can now reach with more adduction of the humerus and the internal rotation starts to decrease as he reaches towards the midline. Reaching in prone is first attempted without supporting on the opposite arm, and is performed with a lot of abduction and internal rotation of the humerus, without adequate fixation of the scapula in adduction. As weight-bearing ability on the supporting arm improves we see more rotation over the supporting arm and, for the first time, dissociation between the movements of the two scapulae. On the supporting side the scapula is stabilised in abduction whilst on the nonweight-bearing side it is stabilised in adduction, allowing reach in more external rotation. At this stage (at about six or seven months) if he attempts to reach in sitting he will revert to reaching in interna! rotation since his trunk control in sitting is still inadequate and he has no point of fixation from which to control his scapula and glenohumeral joint.

\section{RELATIONSHIP TO DISTAL COMPONENTS}

Whilst the baby is still weight-bearing on his elbows in abduction and internal rotation we see pronation of the forearm and ulnar deviation of the wrist; the weight is taken on the flexor aspect of the forearm and the hand is closed. As adduction of the humerus develops, bringing in more external rotation, the rotation of the forearm becomes neutral and weight is taken along the ulnar border of the forearm and hand, allowing some exploratory raking with the fingers. Initial attempts at supporting on extended elbows achieve only partial extension as long as the shoulders remain in abduction and internal rotation, full extension only becoming possible once the humerus can bc stabilised in adduction and external rotation (dependent, in its turn, on stabilisation of the scapula in abduction). As adduction of the humerus increases, the point of weightbearing on the hands moves from the ulnar side across towards the base of the thenar eminence. Initial weightbearing is on flexed fingers, but as the baby brings his base of support in line with his shoulders, getting weight-bearing across the full width of the palm and putting stretch on the wrist and finger flexors, the fingers start to extend and the baby takes weight on an open hand. More important, the pressure on the thenar eminence brings the thumb out of the palm and into abduction in line with the palm, an essential preparation for the development of the use of the radial tripod in manipulation.

Development of the distal components of reach are similarly dependent upon the establishment of proximal components. Until flexor control is sufficiently established to allow good abduction of the scapulae in supine, the arms cannot be brought to the midline and reach is limited. As long as the humerus remains in internal rotation during reach, the forearms remain pronated. This pronation diminishes as the rotation at the shoulder becomes more neutral and by this stage the forearms supinate when the elbows are flexed, as for example when a toy is brought to the mouth. The mature pattern of reach in supine occurs when abduction is sufficiently strong to bring the shoulders off the ground; the humerus is now adducted and externally rotated and the forearm is brought into supination. Only once this pattern has been established does grasp change from a palmar grasp to the use of the radial tripod. Reaching in the prone or prone kneeling positions involves adduction of the scapula, abduction and external rotation of the humerus. extension of the elbow and. as these components become perfected, supination of the forearm. Once again the development of reach in supination depends upon the acquisition of proximal control; the baby initially reaches in pronation. It will be seen that the patterns of mature reach in supine and in prone differ in the combination of scapular and gleno-humeral movement components. In other words, the baby is eventually able to dissociate the movements of scapula and humerus.

\section{References and acknowledgements}

Blacha, S. (1981) Personal communication.

Casaer, P. (1979). Postural behaviour in newborn infants. Clinics in Devel. Med. No. 72, London, William Heinemann.

Mohr, J. (1981). Personal communication.

Sheridan, M. D. (1981). From birth to five years-children's developmental progress, Windsor, Berks., NFER-NeIson.

Acknowledgement is also made to Mary Quinton, of Berne, Switzerland, who first drew the attention of therapists to the importance of normal movement, and to Lois Bly of the United States upon whose work most of the detailed analysis is based.

\section{M.R.C. SYMPOSIUM TO D1SCUSS CARDIOLOGY IN A TROPICAL ENVIRONMENT DURBAN 1 - 3 SEPTEMBER 1982}

Experts from U.S.A., France, England and Italy will discuss hypertension, rheumatic heart disease and cardiomyopathies. A Community Health Session, specifically designed for nurses, health educationalists, physiotherapists, occupational therapists, social workers and doctors involved in community health care and education, will be held on Thursday 2 September. Small group sessions will emphasise prevention, management and rehabilitation of patients suffering from hypertension, rheumatic heart disease and cardiomyopathies. Registration fee R 10 and accommodation at R 15 per night.

Further details from Secretarial S-39, PO Box 70. Tygerberg, 7505 . 